\title{
A Hydrogen Containment Process for Nuclear Thermal Engine Ground testing
}

Ten-See Wang, Eric Stewart, and Francisco Canabal

NASA Marshall Space Flight Center, Huntsville, Alabama

$52^{\text {nd }}$ AIAA/SAE/ASEE Joint Propulsion Conference

July $25-27,2016$

Salt Lake City, Utah 


\section{Acknowledgment}

- This effort was partially supported by the Center Innovation Fund. Andrew Keys is the Center Chief Technologist and Michael Tinker is the Deputy Center Chief Technologist.

- This effort was also partially supported by Advanced Exploration Systems (AES)/ Nuclear Cryogenic Propulsion System (NCPS) project office. Mike Houts is the Research Manager.

- Special thanks is given to Harold Gerrish, POC for Affordable NCPS Development and Qualification Strategy.

- Lisa Griffin of Fluid Dynamics Branch and Mark D'Agostino of Aerosciences Branch

- Daniel Allgood of Stennis Space Center 


\section{Introduction}

- A safe, robust and affordable hydrogen (H2) removal process is necessary to enable the testing required for nuclear thermal propulsion (NTP) engine development.

- A system-level concept had been proposed by burning $\mathrm{H} 2$ and cooling the exhaust with direct water spray. However, it omits first-order physics, creating safety and cost issues concerning the $\mathrm{H} 2$ containment and the large amounts of non-recyclable water.

- A new process is proposed that meets design objectives. The process will be demonstrated with high fidelity computational design and analysis tools with pertinent physical models. 


\section{Objective}

- The objective of this study is to propose a new total hydrogen containment process to enable the testing required for NTP engine development. This $\mathrm{H}_{2}$ removal process comprises of two unit operations: an oxygen-rich burner and a shell-and-tube type of heat exchanger. This new process is demonstrated by simulation of the steadystate operation of the engine firing at nominal conditions. 
- Unstructured-grid, pressure-based, turbulent, finite-rate reacting flow formulation

- Real Fluid Model for multiphase flows

$$
\begin{aligned}
& \frac{\partial \rho}{\partial t}+\frac{\partial}{\partial x_{j}}\left[\rho\left(u_{j}-u_{j g}\right)\right]=0 \\
& \frac{\partial \rho \alpha_{i}}{\partial t}+\frac{\partial}{\partial x_{j}}\left[\rho\left(u_{j}-u_{j g}\right) \alpha_{i}\right]=\frac{\partial}{\partial x_{j}}\left[\left(\rho D+\frac{\mu_{t}}{\sigma_{\alpha}}\right) \frac{\partial \alpha_{i}}{\partial x_{j}}\right]+\omega_{i} \\
& \frac{\partial \rho u_{i}}{\partial t}+\frac{\partial}{\partial x_{j}}\left[\rho\left(u_{j}-u_{j g}\right) u_{i}\right]=-\frac{\partial p}{\partial x_{i}}+\frac{\partial \tau_{i j}}{\partial x_{j}} \\
& \frac{\partial \rho H}{\partial t}+\frac{\partial}{\partial x_{j}}\left[\rho\left(u_{j}-u_{j i}\right) H\right]=\frac{\partial p}{\partial t}+Q_{r}+\frac{\partial}{\partial x_{j}}\left(\left(\frac{K}{C_{D}}+\frac{\mu_{i}}{\sigma_{H}}\right) \nabla H\right)+\frac{\partial}{\partial x_{j}}\left(\left(\left(\mu+\mu_{i}\right)-\left(\frac{K}{C_{D}}+\frac{\mu_{i}}{\sigma_{H}}\right)\right) \nabla\left(V^{2} / 2\right)\right) \\
& +\frac{\partial}{\partial x_{j}}\left(\left(\frac{K}{C_{g}}+\frac{\mu_{i}}{\sigma_{H}}\right)\left(u_{k} \frac{\partial u_{j}}{\partial x_{k}}-\frac{2}{3} u_{j} \frac{\partial u_{k}}{\partial x_{k}}\right)\right) \\
& \frac{\partial \rho k}{\partial t}+\frac{\partial}{\partial x_{j}}\left[\rho\left(u_{j}-u_{j g}\right) k\right]=\frac{\partial}{\partial x_{j}}\left[\left(\mu+\frac{\mu_{t}}{\sigma_{k}}\right) \frac{\partial k}{\partial x_{j}}\right]+\rho(\Pi-\varepsilon) \\
& \frac{\partial \rho \varepsilon}{\partial t}+\frac{\partial}{\partial x_{j}}\left[\rho\left(u_{j}-u_{j g}\right) \varepsilon\right]=\frac{\partial}{\partial x_{j}}\left[\left(\mu+\frac{\mu_{t}}{\sigma_{\varepsilon}}\right) \frac{\partial \varepsilon}{\partial x_{j}}\right]+\rho \frac{\varepsilon}{k}\left(C_{1} \Pi-C_{2} \varepsilon+C_{3} \Pi^{2} / \varepsilon\right)
\end{aligned}
$$




\section{Heat Exchanger Sizing Methodology}

$\frac{d \rho}{\rho}+\frac{d u}{u}=0$

$d p+\frac{4 \tau_{w} d x}{D}+\rho u d u=0$

$\dot{Q}=\dot{m}\left(i_{2}+\frac{1}{2} u_{2}^{2}-i_{1}-\frac{1}{2} u_{1}^{2}\right)$

The power transfer is calculated with Newton's law of cooling as given by:

$\dot{Q}=h A\left(T_{w}-T_{m}\right)$

The local Nusselt number, used to determine the heat transfer coefficient, is obtained from the Gnielinski equation:

$N u_{D}=\frac{(f / 8)\left(R e_{D}-1000\right) P r}{1+12.7(f / 8)^{1 / 2}\left(P^{2 / 3}-1\right)}$

Where the Moody friction factor for a smooth wall is given as a function of Reynolds number by the Petukhov equation:

$f=\left(0.790 \ln \left(R e_{D}\right)-1.64\right)^{-2}$

Which is also used to define the wall shear stress as:

$\tau_{w}=f\left(\frac{\rho u_{m}^{2}}{8}\right)$

The software Cequel ${ }^{\mathrm{TM}}$ (Chemical Equilibrium in Excel), provides the remaining required equation of state functionality and relations for the transport and thermodynamic properties of the combustion gases, which are allowed to dissociate and recombined through the tube assuming equilibrium throughout. 


\section{Total Hydrogen Containment Process}

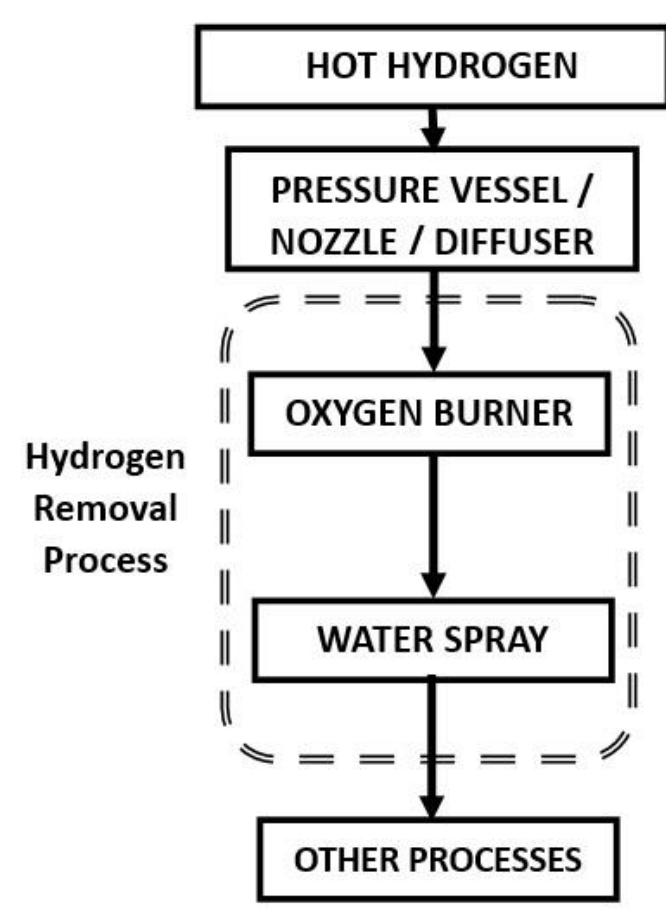

Current process based on system-level model.

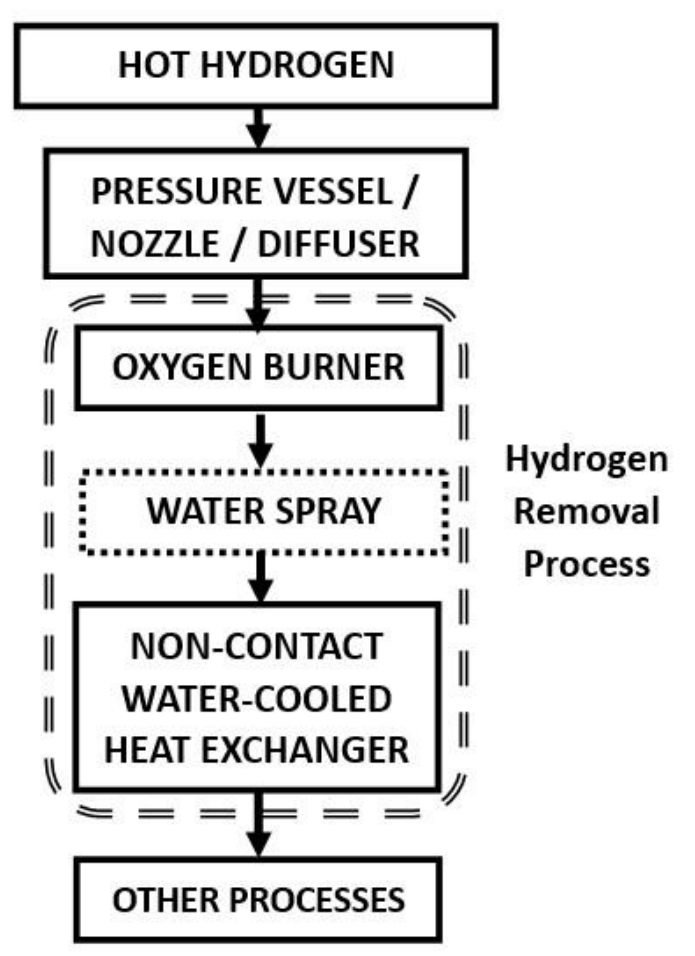

The proposed new hydrogen removal process based on the CFD model. 


\section{Conceptual Design}

Conceptual Design Goals

- Oxygen-Rich Burner design goal: 99\% reduction of hydrogen

- Straight-cylinder burner size

- State of inlet oxygen

- O/F ratio

- Heat exchanger design goal: $1 \%$ reduction of hydrogen

- Shell-and-tube tubular heat exchanger

- Cooling tube size

- Number of cooling tubes

- Layout of cooling tubes

- Hydrogen removal process goal: computed flammability < LFL

\section{Lower Flammability Limit}

The hydrogen and oxygen mixture can not be ignited if the percent of hydrogen in the mixture (less steam) is less than the lower flammability limit (LFL), or higher than the upper flammability limit (UFL). The flammability limits based on the volume percent of hydrogen in oxygen at $14.7 \mathrm{psia}(1 \mathrm{~atm}, 101 \mathrm{kPa})$ are 4.0 and 94.0 [25]. Converting to mass percent of hydrogen in oxygen, the LFL and UFL are $0.2618 \%$ and $49.67 \%$, respectively. Since the idea of the oxygenrich burner is to burn off hydrogen as much as possible near the end of the burner, UFL is therefore not applicable and the goal is to reduce the mass of hydrogen in dry mixture to a value lower than the LFL. Note that the auto-ignition temperature of hydrogen is $773 \mathrm{deg}$. K.

The flammability is calculated as:

$$
\text { flammability }=\frac{\alpha_{H_{2}}+\alpha_{H}+\alpha_{O H}\left(M_{H} / M_{O H}\right)}{\alpha_{O_{2}}+\alpha_{O}+\alpha_{H_{2}}+\alpha_{H}+\alpha_{O H}}
$$




\section{Axisymmetric Grid \& Computational Domain}

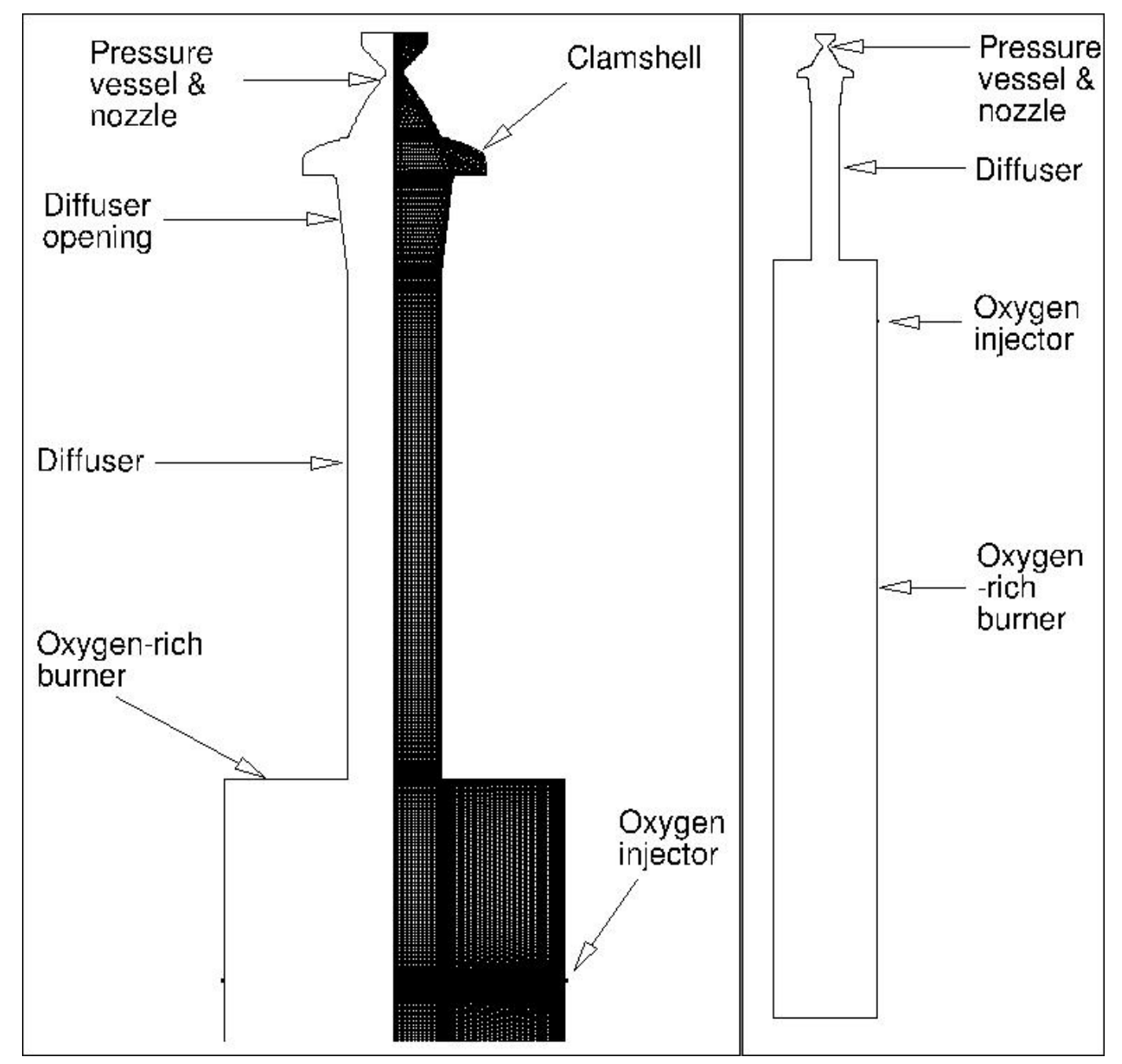




\begin{tabular}{|c|c|r|r|r|c|c|c|}
\hline Case & $\mathrm{O} / \mathrm{F}$ & $\mathrm{R} / \mathrm{R}_{\circ}$ & $\mathrm{L} / \mathrm{L}_{\circ}$ & $\mathrm{T}_{02}$ inlet $\mathrm{T}_{\circ}$ & $\mathrm{O} 2$ injector geometry & Burner geometry & $\begin{array}{l}\text { Ave exit H2 mass } \\
\text { fraction, \% }\end{array}$ \\
\hline 1 & 9 & 36 & 705 & 90 & Duct & Straight cylinder & 5.81 \\
\hline 2 & 9 & 46 & 940 & 90 & Duct & Straight cylinder & 3.86 \\
\hline 3 & 9 & 46 & 940 & 90 & Duct & $\begin{array}{c}\text { Straight cylinder with a } \\
\text { long wall fin }\end{array}$ & 3.56 \\
\hline 4 & 9 & 46 & 940 & 300 & Sonic nozzle & Straight cylinder & 4.27 \\
\hline 5 & 9 & 65 & 940 & 90 & Duct & Straight cylinder & 3.92 \\
\hline 6 & 9 & 65 & 940 & 200 & Duct & Straight cylinder & 3.61 \\
\hline 7 & 9 & 65 & 940 & 200 & Sonic nozzle & Straight cylinder & 4.46 \\
\hline 8 & 9 & 65 & 940 & 300 & Sonic nozzle & Straight cylinder & 2.58 \\
\hline 9 & 9 & 65 & 940 & 300 & Swirled sonic nozzle & Straight cylinder & 5.84 \\
\hline 10 & 12.5 & 65 & 940 & 300 & Sonic nozzle & Straight cylinder & 0.96 \\
\hline
\end{tabular}

This CFD parametric study results show the importance of inter-connected physics such as turbulent mixing, finite-rate chemistry, and residence times that are driven by design parameters such as geometry, $\mathrm{O} / \mathrm{F}$ ratio, and state of oxygen. It also shows the importance of having a CFD-based process design such that achieving the design objective of the specialized process could be simulated and demonstrated. 

Pressure Vessel \& Nozzle/Diffuser/burner CFD Parametric Study

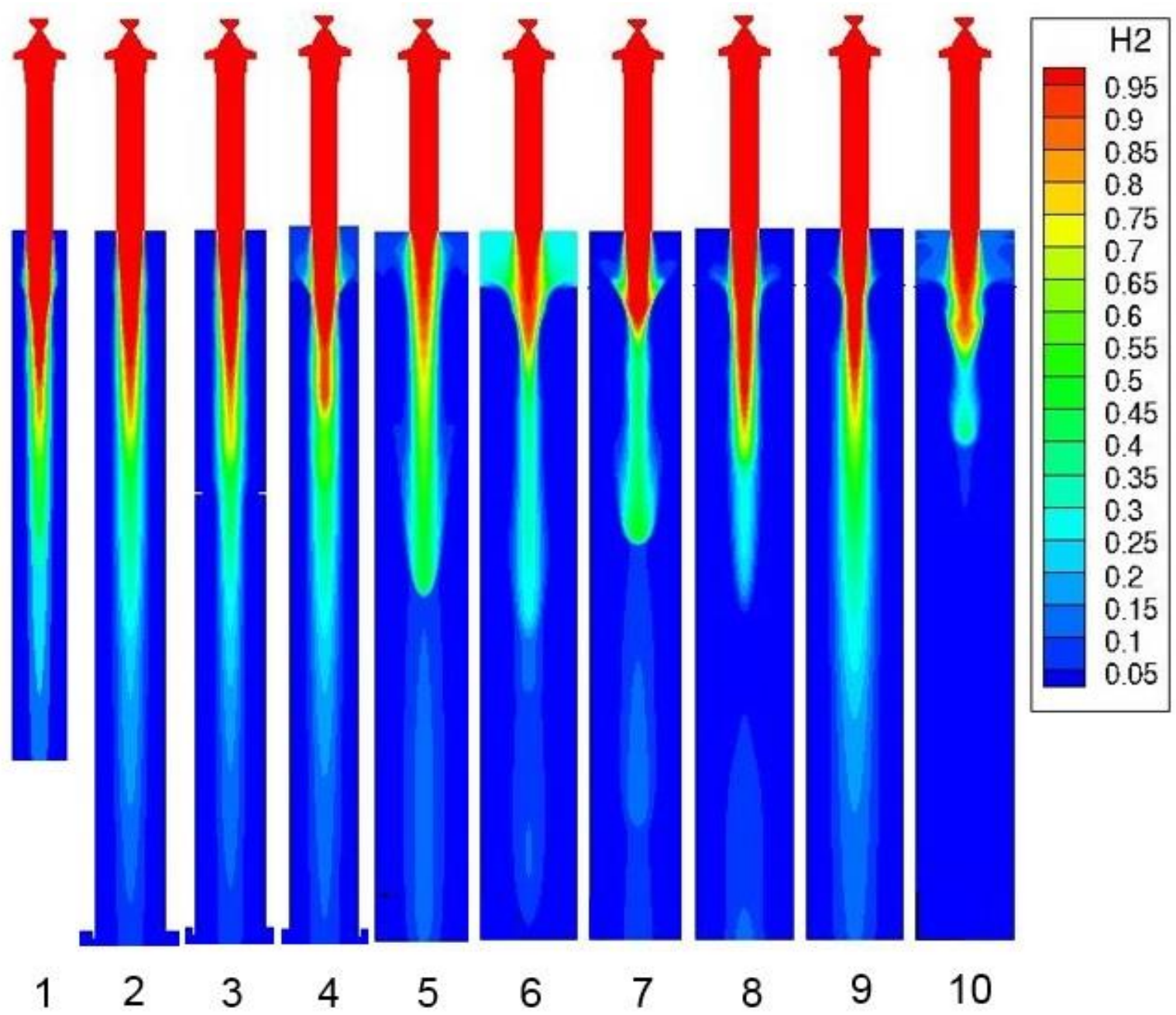




\begin{tabular}{|c|c|c|c|c|}
\hline Case & A & B & C & D \\
\hline$\dot{\mathrm{m}} / \dot{\mathrm{m}}_{\circ}$ & 1.00 & 0.50 & 0.10 & 0.05 \\
\hline $\mathrm{T}_{\mathrm{in}} / \mathrm{T}_{\circ}$ & 3,331 & 3,331 & 3,331 & 3,331 \\
\hline $\mathrm{T}_{\text {out }} / \mathrm{T}_{\circ}$ & $1,053.5$ & 947.1 & 733.1 & 400 \\
\hline $\mathrm{T}_{\text {wall }} / \mathrm{T}_{\circ}$ & 400 & 400 & 400 & 0.1016 \\
\hline $\mathrm{D} / \mathrm{D}_{\circ}$ & 0.1016 & 0.1016 & 0.1016 & 14.732 \\
\hline $\mathrm{L} / \mathrm{L}_{\circ}$ & 14.732 & 14.732 & 14.732 & 5,748 \\
\hline $\mathrm{Re}_{\text {in }}$ & 114,969 & 57,485 & 11,497 & 21,771 \\
\hline $\mathrm{Re}_{\text {out }}$ & 286,453 & 156,883 & 39,410 & 0.028 \\
\hline $\mathrm{Mach}_{\text {in }}$ & 0.568 & 0.284 & 0.057 & 0.011 \\
\hline $\mathrm{Mach}$ out & 0.283 & 0.130 & 0.023 & 145.0 \\
\hline $\mathrm{L} / \mathrm{D}$ & 145.0 & 145.0 & 145.0 & \\
\hline
\end{tabular}

Case $\mathrm{C}$ is chosen as a nominal case for the demonstrative computation among many possible cases. The heat exchanger sizing tool is a fast, one-dimensional thermal system model. Although more physics have been added, it still uses assumptions such as equilibrium chemistry. To be conservative and considering those assumptions, the actual L/D designed was therefore increased from 145 to 230. 
Axisymmetric, Integrated Pressure Vessel \&

Nozzle/Diffuser/Burner and Single Cooling Tube CFD Results

\begin{tabular}{|c|c|c|c|c|}
\hline Case & $\mathrm{O} / \mathrm{F}$ & $\dot{\mathrm{m}} / \dot{\mathrm{m}}_{\circ}$ & Flammability \% & $\begin{array}{c}\text { Flammability } \%< \\
\text { LFL? }\end{array}$ \\
\hline 1 & 12.5 & 0.1 & 0.00193 & Yes \\
\hline 2 & 12.5 & 0.2 & 0.01288 & Yes \\
\hline 3 & 12.5 & 0.3 & 0.03247 & Yes \\
\hline 4 & 12.5 & 0.4 & 0.05406 & Yes \\
\hline
\end{tabular}

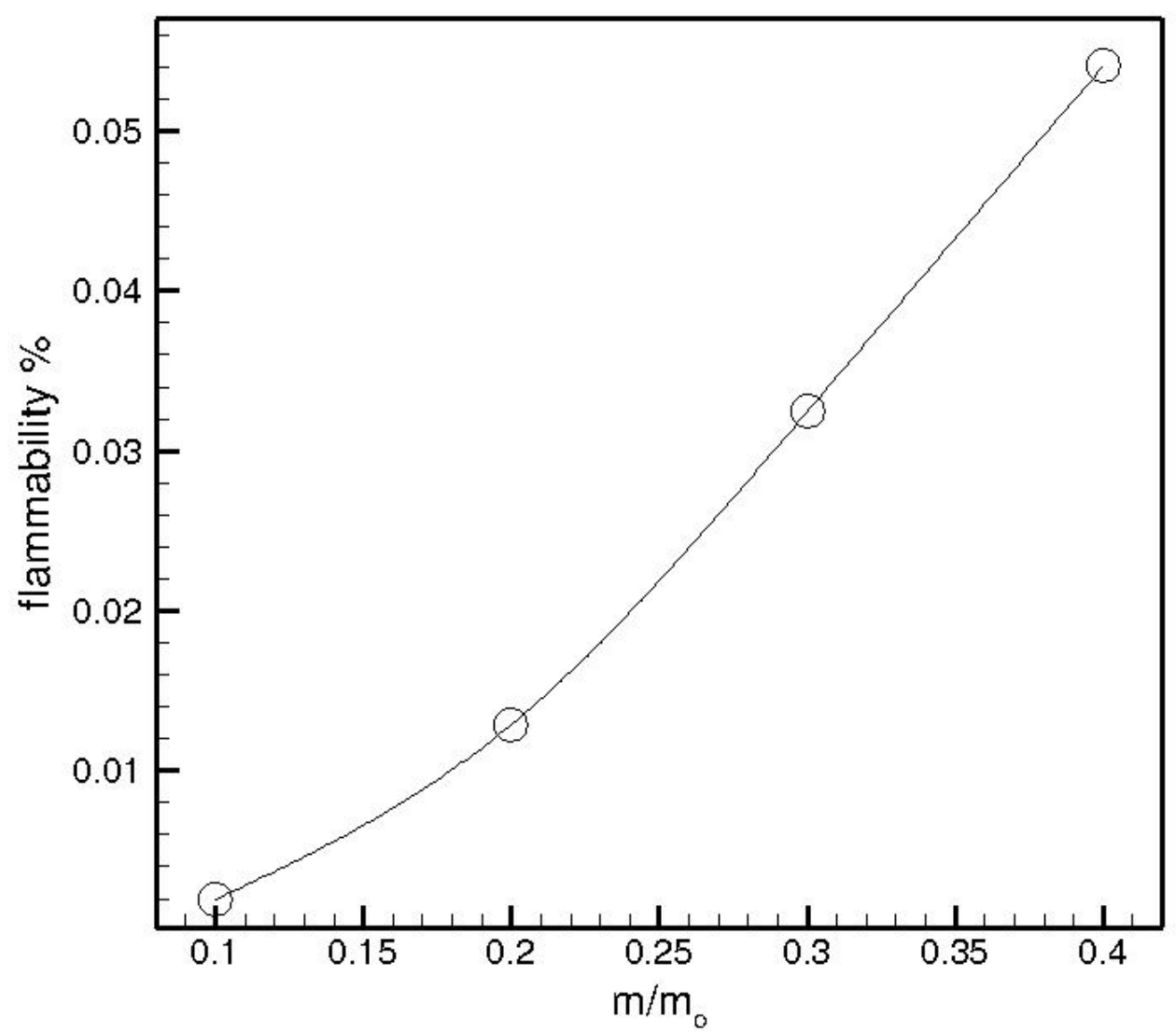

$\mathrm{LFL}=0.2618 \%$ 


\section{Nozzle/Diffuser/Burner/Heat Exchanger CFD Results}

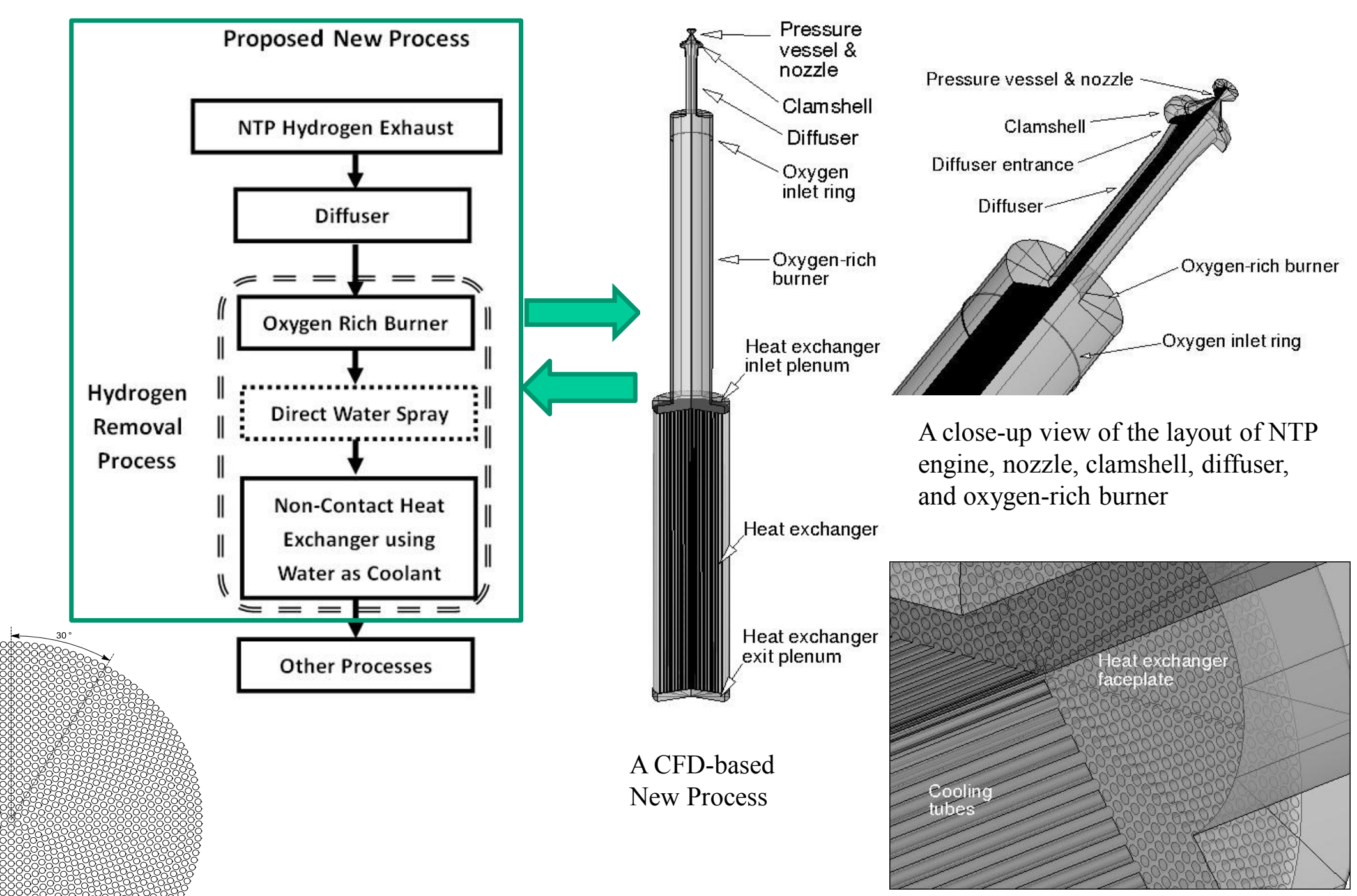

A close-up view of the layout of heat exchanger faceplate and cooling tubes 


\section{Nozzle/Diffuser/Burner/Heat Exchanger CFD Results}
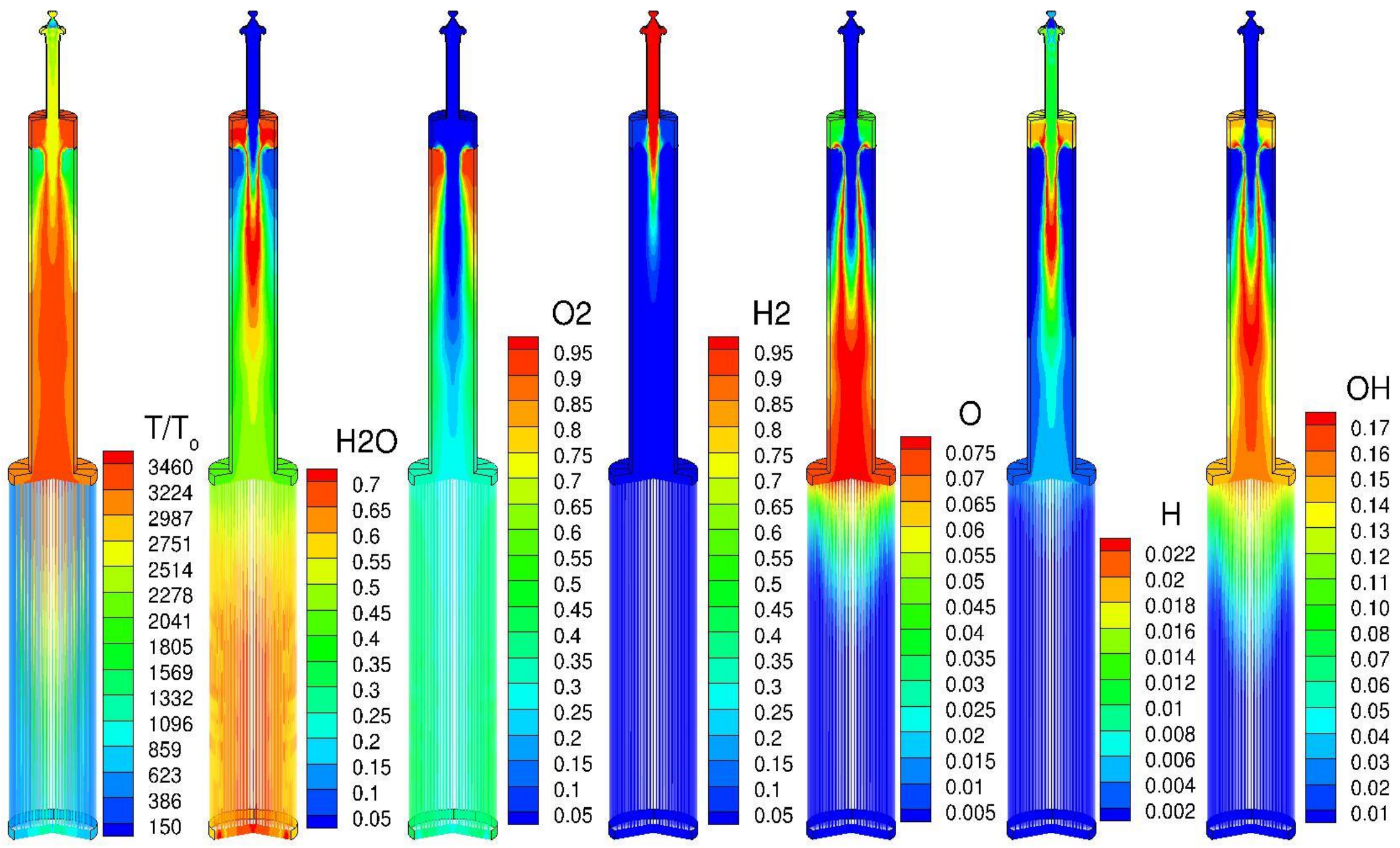

Computed temperature and species concentration contours on the symmetry plane for the entire three-dimensional process 


\section{Nozzle/Diffuser/Burner/Heat Exchanger CFD Results}
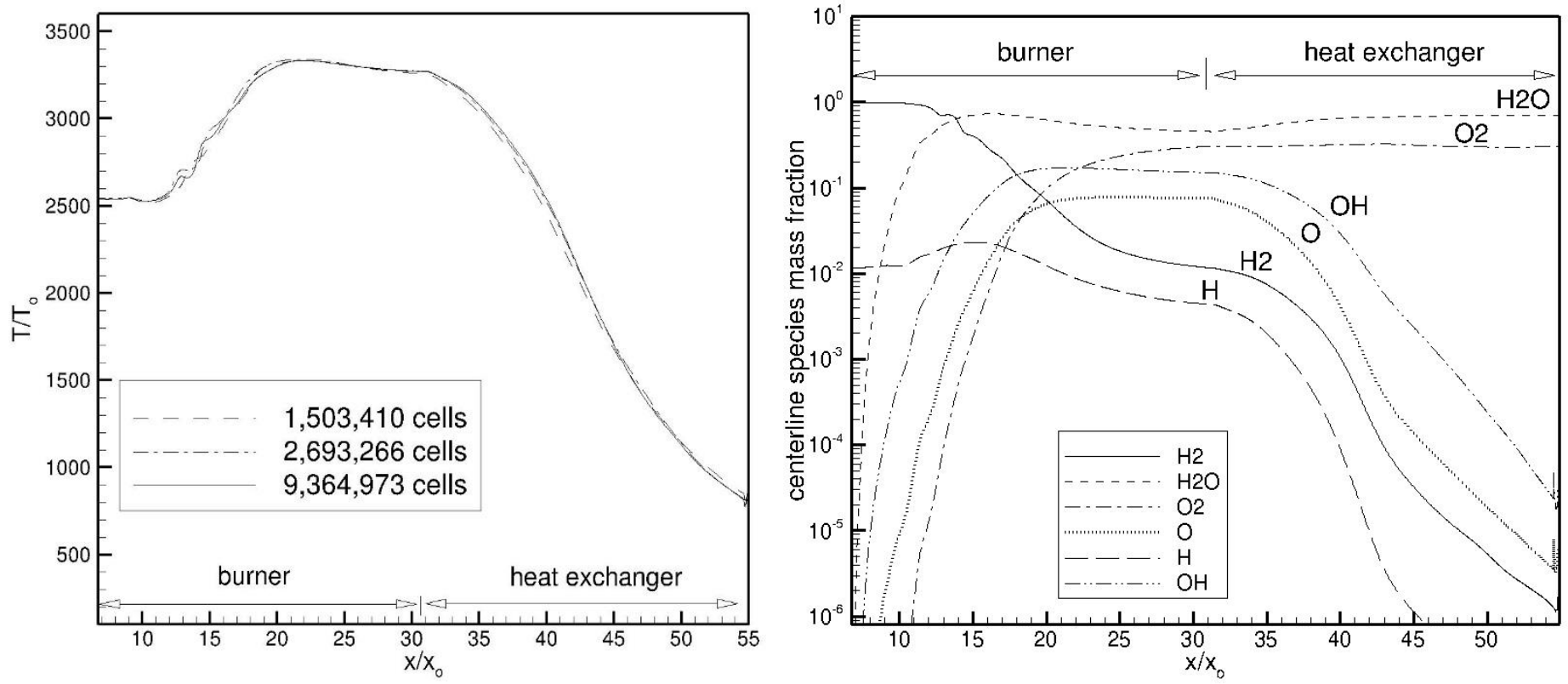

Likely recombination reactions in heat exchanger:

$\mathrm{OH}+\mathrm{H} 2=\mathrm{H} 2 \mathrm{O}+\mathrm{H}$

$\mathrm{OH}+\mathrm{OH}=\mathrm{O}+\mathrm{H} 2 \mathrm{O}$

$\mathrm{H}+\mathrm{OH}=\mathrm{H} 2 \mathrm{O}$

Final flammability computed at the exit plane of the heat exchanger from three grid cell sizes. The flammability results show that $\mathrm{H} 2$ total containment objective has been met with the proposed process.

\begin{tabular}{|c|c|c|c|}
\hline Case & Cell numbers & $\begin{array}{c}\text { Flammability } \\
\%\end{array}$ & $\begin{array}{c}\text { Flammability \% } \\
<\mathbf{0 . 2 6 1 8 \%} \%\end{array}$ \\
\hline 1 & $1,503,410$ & 0.00300 & Yes \\
\hline 2 & $2,693,266$ & 0.00204 & Yes \\
\hline 3 & $9,364,973$ & 0.00199 & Yes \\
\hline
\end{tabular}




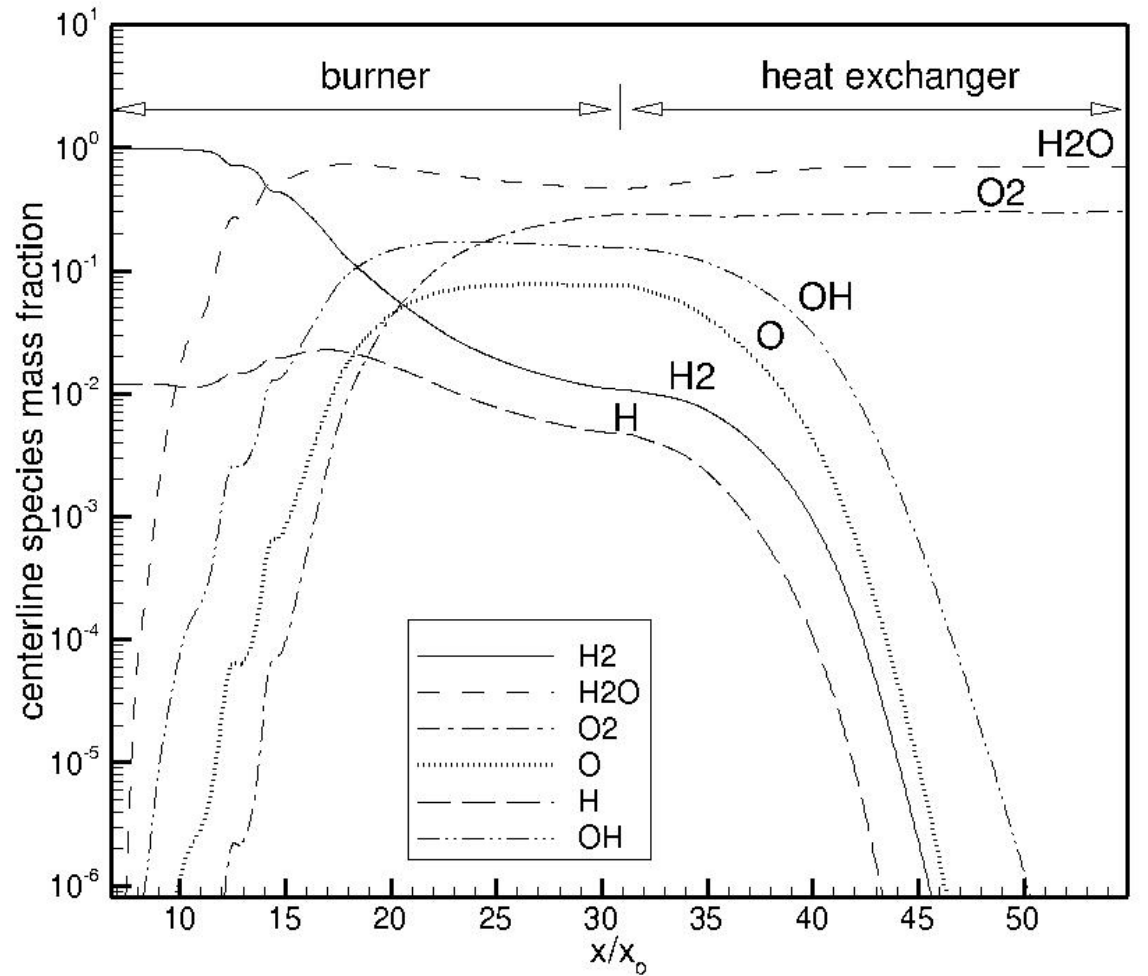

Equilirbium chemistry

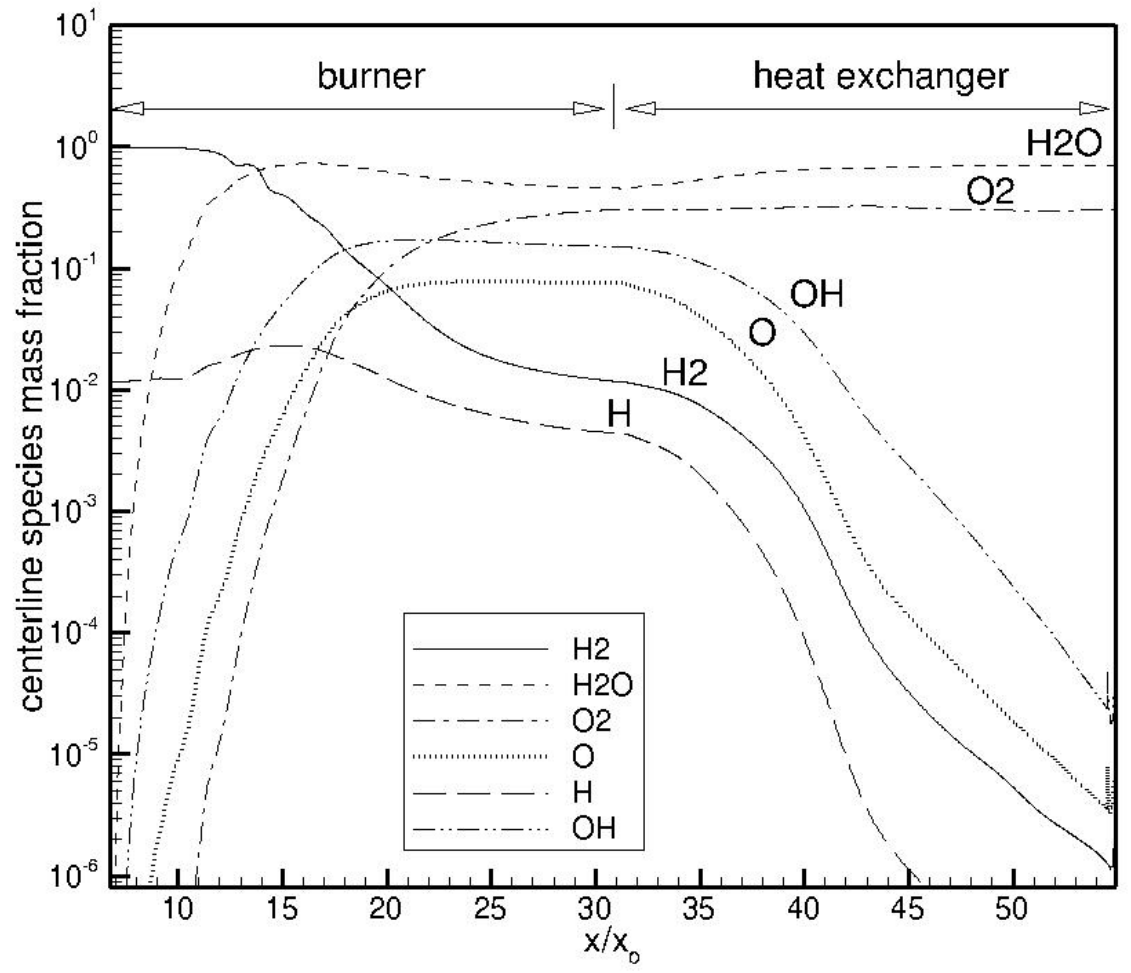

Finite-rate chemistry 
Nozzle/Diffuser/Burner/Heat Exchanger CFD Results

A comparison of species mass fractions and flammability at end of heat exchanger

\begin{tabular}{|l|c|c|}
\hline species & Finite-rate chemistry & Equilibrium chemistry \\
\hline $\mathrm{H}_{2}$ & $0.34568 \mathrm{E}-05$ & $0.80734 \mathrm{E}-11$ \\
\hline $\mathrm{H} 2 \mathrm{O}$ & 0.69773 & 0.70294 \\
\hline $\mathrm{O} 2$ & 0.30213 & 0.29706 \\
\hline $\mathrm{O}$ & $0.12130 \mathrm{E}-04$ & $0.27250 \mathrm{E}-10$ \\
\hline $\mathrm{H}$ & $0.15387 \mathrm{E}-06$ & $0.54466 \mathrm{E}-15$ \\
\hline $\mathrm{OH}$ & $0.12058 \mathrm{E}-03$ & $0.17619 \mathrm{E}-06$ \\
\hline & & \\
\hline Flammability $\%$ & 0.00199 & $9.0070 \mathrm{E}-06$ \\
\hline
\end{tabular}

Equilirbium chemistry assumes infinite residence time by assuming infinite reaction rates. Result shows the importance of residence times. 


\section{Conclusions}

- A computational fluid dynamics based hydrogen containment process is proposed using a non-contact heat exchanger in lieu of direct water spray for better cooling efficiency and recyclable water (without the need for storing a large amount of water).

- The computed flammability at the end of heat exchanger is less than that of the lower flammability limit, demonstrating the total hydrogen containment capability of the proposed process. 